\title{
A Weak Allele of FASCIATED EAR 2 (FEA2) Increases Maize Kernel Row Number (KRN) and Yield in Elite Maize Hybrids
}

\author{
Khuat Huu Trung ${ }^{1}$, Quan Hong Tran ${ }^{1}$, Ngoc Hong Bui ${ }^{1}$, Thuy Thi Tran ${ }^{1}$, Kong Quy Luu ${ }^{2}$, \\ Nga Thi Thu Tran ${ }^{3}$, Loan Thi Nguyen ${ }^{1}$, Diep Thi Ngoc Nguyen ${ }^{3}$, Bach Duong Vu ${ }^{2}$, \\ Duong Thi Thuy Quan ${ }^{1}$, Diep Thuy Nguyen ${ }^{1}$, Hien Thi Nguyen ${ }^{3}$, Cuong Cao Dang ${ }^{3}$, \\ Bao Manh Tran ${ }^{3}$, Tran Dang Khanh ${ }^{1,4}$ (D) and Son Lang Vi ${ }^{2,5, *}$ \\ 1 Department of Genetic Engineering, The Agricultural Genetics Institute, Km2 Pham Van Dong Street, \\ Hanoi 122000, Vietnam; khuathuutrung@yahoo.com (K.H.T.); quan.th.93@gmail.com (Q.H.T.); \\ buihongngoctb@gmail.com (N.H.B.); thuy80vdt@gmail.com (T.T.T.); nguyenloan0110@gmail.com (L.T.N.); \\ quanthithuyduong01121997@gmail.com (D.T.T.Q.); nguyenthuydiep2002@yahoo.com (D.T.N.); \\ khanhkonkuk@gmail.com (T.D.K.) \\ 2 Faculty of Biotechnology, Chemistry and Environmental Engineering, PHENIKAA University, Yen Nghia, \\ Ha Dong, Hanoi 12116, Vietnam; luuquykong_s15@hus.edu.vn (K.Q.L.); \\ sutuhadong.2009@gmail.com (B.D.V.) \\ 3 ThaiBinh Seed Group Joint StockCompany, 36 Quang Trung Street, Phuong Tran Hung Dao, \\ Thai Binh 410000, Vietnam; tranthunga@thaibinhseed.vn (N.T.T.T.); \\ ngocdiepkhctdk56@gmail.com (D.T.N.N.); hiennt.bvtv@gmail.com (H.T.N.); \\ dangcaocuong@thaibinhseed.vn (C.C.D.); tranmanhbao.tsc@gmail.com (B.M.T.) \\ 4 Center for Agricultural Innovation, Vietnam National University of Agriculture, Hanoi 131000, Vietnam \\ 5 PHENIKAA Research and Technology Institue (PRATI), A\&A Green Phoenix Group JSC, \\ No. 167 Hoang Ngan, Trung Hoa, Cau Giay, Hanoi 11313, Vietnam \\ * Correspondence: son.vilang@phenikaa-uni.edu.vn; Tel./Fax: +84-90-320-2285
}

Received: 30 September 2020; Accepted: 9 November 2020; Published: 13 November 2020

check for updates

\begin{abstract}
Meristems are central to plant growth and development, yet evidence of directly manipulating this control to improve crop yield is scarce. Kernel row number (KRN) is an important agronomic trait that can directly affect maize (Zea mays L.) yield. However, this trait is difficult to select by phenotyping, since it is highly variable in the mixed genetic backgrounds in early selfing generations. This study sought to improve this trait by marker-assisted backcrossing (MABC) of a weak allele of FASCIATED EAR 2 that is known to affect inflorescence meristem size, but the effect of which on yield is unclear. All of the four introgressed tropical elite inbreds of different heterotic groups, which are homozygous for the fea2-1328 allele, had 2-5 more KRNs compared to their respective recurrent parents. Furthermore, one hybrid made from crosses between two introgressed parents also had KRN increases that resulted in up to $28 \%$ yield increase compared to the original hybrid across multiple yield trials. The novel negative effects of the pericentromeric fea 2 and/or its linkage drag effect on plant height, seed weight, and ear length, which could prevent line improvement, were revealed in several genetic backgrounds. Integration of conventional phenotypic selection to overcome these undesirable effects was discussed. This is the first work to demonstrate the possibility to increase yield of maize varieties using a mutation in a meristem size regulator. The crossing, selection strategies, and recombinant lines in this work can be applied to other elite maize hybrids and provide a potentially straightforward, non-transgenic way to improve the yield of an existing variety by $8-28 \%$.
\end{abstract}

Keywords: maize yield; marker assisted selection; backcross; MAS; kernel row number; KRN; FEA2 


\section{Introduction}

Maize (Zea mays L.) is one of the most important crops and is providing billions of dollars annually to agriculture, supplying over $30 \%$ of the calories consumed by humans [1]. Maize is cultivated in over 165 countries under different complex agroclimatic conditions, with a total global harvest area of approximately 187 million hectares, and producing 1.14 billion tonnes worldwide [1,2]. In the last century, yields of maize and its quality have been significantly increased via conventional and advanced hybrid programs. However, the adverse impacts of climate change on both abiotic and biotic stresses, such as temperature increase, changes in precipitation patterns, and pests/disease infestations, have significantly reduced worldwide maize productivity $[3,4]$. Notwithstanding, the demand for maize has steadily increased in recent decades and is expected to continue to rise, with estimated maize consumption to double by $2050[2,5]$.

In Vietnam, maize is the second biggest annual crop after rice in terms of harvested area and is consumed for animal feed in the livestock and poultry industry. This crop is cultivated in diverse environments of both rainfed upland and irrigated lowland areas in the northeast, northwest, central highlands, and southeast regions [6]. Maize production and harvested areas increased almost 3-fold from 0.43 million ha in 1990 to 1.18 million ha in 2014, with remarkable yield increases from 1.55 to over $4.0 \mathrm{t} \mathrm{ha}^{-1}$ [7]. However, maize yield in Vietnam is still lower compared with global averages due to both breeding and agriculture practices. Since maize is a crop that exhibits strong heterosis, maize breeding often involves developing the best inbred lines with good characteristics and high combining ability to make hybrids [8]. Once a good pair of parents from opposite heterotic groups have been selected, the further improvement of this hybrid will focus on improving each parent/both parents without affecting their combining ability [8]. Therefore, backcross is often used to improve an existing elite maize variety.

Marker-assisted backcrossing (MABC) is a useful strategy to introduce a new trait to a variety [9]. This method uses molecular markers to track a locus of interest so the trait can be selected based on genotype. The loci of interest from a donor parent (DP) are transferred to a recurrent parent (RP) by repeated backcrosses to the RP. This approach has successfully improved several traits, such as protein quality using opaque 2 and opaque 16 markers [10,11], beta-carotenoid content using CrtRB1 and LcyE markers [10,12-14], disease resistance [15-17], oil content [18], and drought tolerance [19-21]. For introducing a recessive trait, backcrossing must be carried out in both parents.

Yield of maize is a complex quantitative trait determined by multiple component traits, such as number of ears per plant, kernel weight (KW), kernel row number (KRN), and number of kernels per row [22]. Of these, KRN is one of the most important traits and a key target for breeders [23-25]. QTL (Quantitative Trait Loci) that control KRN and yield have been studied extensively [22,26-30], and some of them have been cloned [23,25].

FASCIATED EAR 2 was cloned from a maize mutant with fasciated ear tips [31]. FEA2 is homologous to CLAVATA2 from Arabidopsis, and encodes a leucine-rich repeat receptor-like protein (LRR-RLP) that acts as a negative regulator of inflorescences' meristem proliferation and size. Bommert, Nagasawa, and Jackson [23] showed that FEA2 underlies a KRN QTL in a B73/Mo17 RIL (Recombinant Inbred Line) population. Although null fea2 mutants have enlarged and deformed ear tips and short ears with disorganized rows, a TILLING (Targeting Induced Local Lesions in Genomes) approach identified several alleles of FEA2 with normal shaped ears and increased KRN. The fea2-1328 allele was found to have the strongest effect, with an increase of approximately three KRN, without reducing ear length. However, the impact this allele has on overall yield, or its effect in other genetic backgrounds, is unknown.

The idea of increasing KRN to improve yield is controversial because without increasing overall photosynthesis capability, increasing KRN may lead to a compensatory shortening of ears and/or smaller seeds, without a yield increase. Hence, the impacts on maize yield by favorable KRN QTLs in different genetic backgrounds have remained uncertain. Therefore, we investigated the potential to 
increase KRN and yield of elite tropical maize germplasms and their hybrids using a weak fea2 allele, and showed that indeed, this can lead to yield increases.

\section{Materials and Methods}

\subsection{Plant Materials}

LVN10 and VS36 are two elite maize hybrids that are being commercialized in Vietnam [32,33]. Both maize hybrids are well adapted to many cultivating areas of this country and there is a demand to improve their yield. ML10, BL10, MVS36, and BVS36 are maternal parents (ML10, MVS36) and paternal parents (BL10, BVS36) of two elite maize hybrids, LVN10 and VS36, respectively. These parents were generated by Vietnamese researchers via traditional selfing and phenotypic selection methods. ML10, of which a genome has been re-sequenced, has been extensively used in Vietnamese maize breeding programs and to generate a mutation population [32]. The four parental inbreds belong to the different heterotic groups. All fea2 alleles inW22 background were provided by David Jackson, CSHL, New York, USA [23]. For phenotypic measurements of parental introgression lines (ILs), several homozygous fea2-1328-/- $\mathrm{BC}_{3} \mathrm{~F}_{3}$ families were used. For the LVN10 fea2-/- hybrid, homozygous parental lines from $\mathrm{BC}_{3} \mathrm{~F}_{\mathrm{X}} \mathrm{IL}$ and $\mathrm{BC}_{3} \mathrm{~F}_{\mathrm{x}} \mathrm{IL}$ families were used to make crosses; with " $\mathrm{X}$ " refers to the selfing generation. The hybrid seeds LVN10 fea2-/- used in the Thai Binh Spring cropping season in 2017 were ML10-IL1 $\left(\mathrm{BC}_{3} \mathrm{~F}_{3}\right)$, crossed by BL10-IL1 $\left(\mathrm{BC}_{3} \mathrm{~F}_{3}\right)$. The seeds used in Thai Binh in Autumn 2017 and Son La in Summer 2018 were ML10 BC ${ }_{3} F_{4}$ (derived from selfed ML10-IL1 $\left(B_{3} F_{3}\right)$ ) $\times$ BL10 $\mathrm{BC}_{3} \mathrm{~F}_{4}$ (derived from selfed BL10-IL1 $\left(\mathrm{BC}_{3} \mathrm{~F}_{3}\right)$ ). The seeds used in Ha Noi and Thai Binh in Spring 2020 were ML10 $\mathrm{BC}_{3} \mathrm{~F}_{6} \times \mathrm{BL}_{10} \mathrm{BC}_{3} \mathrm{~F}_{6}$. All materials are available for research and breeding via MTA (Material Transfer Agreement) by directly contacting Son Lang Vi.

\subsection{Field Growing Conditions, Agronomic Trait Measurements, and Yield Trial}

Maize was grown on fields in Ha Noi $\left(21^{\circ} 06^{\prime} 19.3^{\prime \prime} \mathrm{N}, 105^{\circ} 49^{\prime} 32.2^{\prime \prime} \mathrm{E}\right)$, Thai Binh $\left(20^{\circ} 33^{\prime} 44.8^{\prime \prime} \mathrm{N}\right.$, $\left.106^{\circ} 24^{\prime} 35.6^{\prime \prime} \mathrm{E}\right)$, and Son La province $\left(21^{\circ} 13^{\prime} 53.8^{\prime \prime} \mathrm{N}, 103^{\circ} 57^{\prime} 37.8^{\prime \prime} \mathrm{E}\right)$, Vietnam. Spring crop seasons are Feb-Jun; Autumn seasons are Sep-Jan; Summer seasons are May-Sep. Fertilizer was applied at the rate of $150 \mathrm{~kg} \mathrm{~N}, 90 \mathrm{~kg} \mathrm{P} \mathrm{P}_{5}$, and $90 \mathrm{~kg} \mathrm{~K} \mathrm{O}_{2}$ per ha. All $\mathrm{P}_{2} \mathrm{O}_{5}$ was applied at planting, and then, $\mathrm{N}$ and $\mathrm{K}_{2} \mathrm{O}$ were applied twice at 20 days (6-leaf stages) and 50 days (before bolting stages) after planting.

Yield trials and phenotypic measurements were carried out following the randomized complete block design. For inbreds and introgression lines, each line was planted using one replicate. For hybrids, each genotype was replicated at least three times. For each replicate, an entry was planted in four-row plots, $5 \mathrm{~m}$ long, with $0.75 \mathrm{~m}$ spacing between rows and $0.25 \mathrm{~m}$ between plants in a row. Only two middle rows were used for measurements of yield and other traits.

For yield calculation: Yield was calculated as: $(\mathrm{P} 3 \times \mathrm{P} 1) \times 10,000 /(\mathrm{P} 2 \times n \times 0.75 \times 0.25) \mathrm{kg} / \mathrm{ha}$.

- $n$ is the total number of plants in the two middle rows.

- $\quad \mathrm{P} 1$ is the sum weight of all the fresh effective ears, which includes both the first and second ears that have more than 20 kernels, from the two middle rows (kg).

- $\quad$ P2 is the sum fresh weight of the ears from sample plants $(\mathrm{kg})$. Twenty plants (ten consecutive plants from the 5th to the 14th from each of the two middle rows) per genotype were taken as the sample plants.

- $\quad \mathrm{P} 3$ is the weight of the resulting dry seeds (at $14 \%$ humidity) from sample plants (kg).

For plant trait measurements, measurements were performed using sample plants only. Plant height, ear height, tassel branch number, kernel row number, ear length, and 1000 dry seed weight (at $14 \%$ humidity) were measured as follows. Plant height- the distance from the base of the plant to the height of the first tassel branch; ear height- the distance from the base of the plant to the node of the highest effective ear; tassel branch number - the number of primary branches; kernel row number-determined at the middle 
of the ear. For most entry, at least 20 plants ( $n \geq 20$ ) were used for measurements). For 1000 dry seed weight, measurements were repeated three times on pooled seeds from all sample plants $(n \geq 3)$.

\subsection{Marker-Assisted Backcrossing}

The scheme of applying MABC is shown in Figure 1a. The mutant fea2-1328 with a W22 inbred background was used as a donor parent (DP) and ML10, BL10, MVS36, and BVS36 inbreds were used as recurrent parents (RPs). Homozygous mutants of fea2-1328 (W22) were crossed to RP to create $\mathrm{F}_{1}$, which were then backcrossed to the corresponding $\mathrm{RP}$ to make $\mathrm{BC}_{1} \mathrm{~F}_{1}$. Genotyped heterozygous $\mathrm{BC}_{1} \mathrm{~F}_{1}$ s that phenotypically resembled the RP the most were backcrossed to the RP to develop $\mathrm{BC}_{2} \mathrm{~F}_{1}$. This backcross process was repeated to obtain $\mathrm{BC}_{3} \mathrm{~F}_{1}$. The $\mathrm{BC}_{3} \mathrm{~F}_{1}$ s were selfed to make $\mathrm{BC}_{3} \mathrm{~F}_{2} \mathrm{~S}$, which were genotyped to find the homozygous type. Homozygous $\mathrm{BC}_{3} \mathrm{~F}_{3} \mathrm{~s}$ were selfed for further generations and selected based on the similarity to the RP and homogeneity.

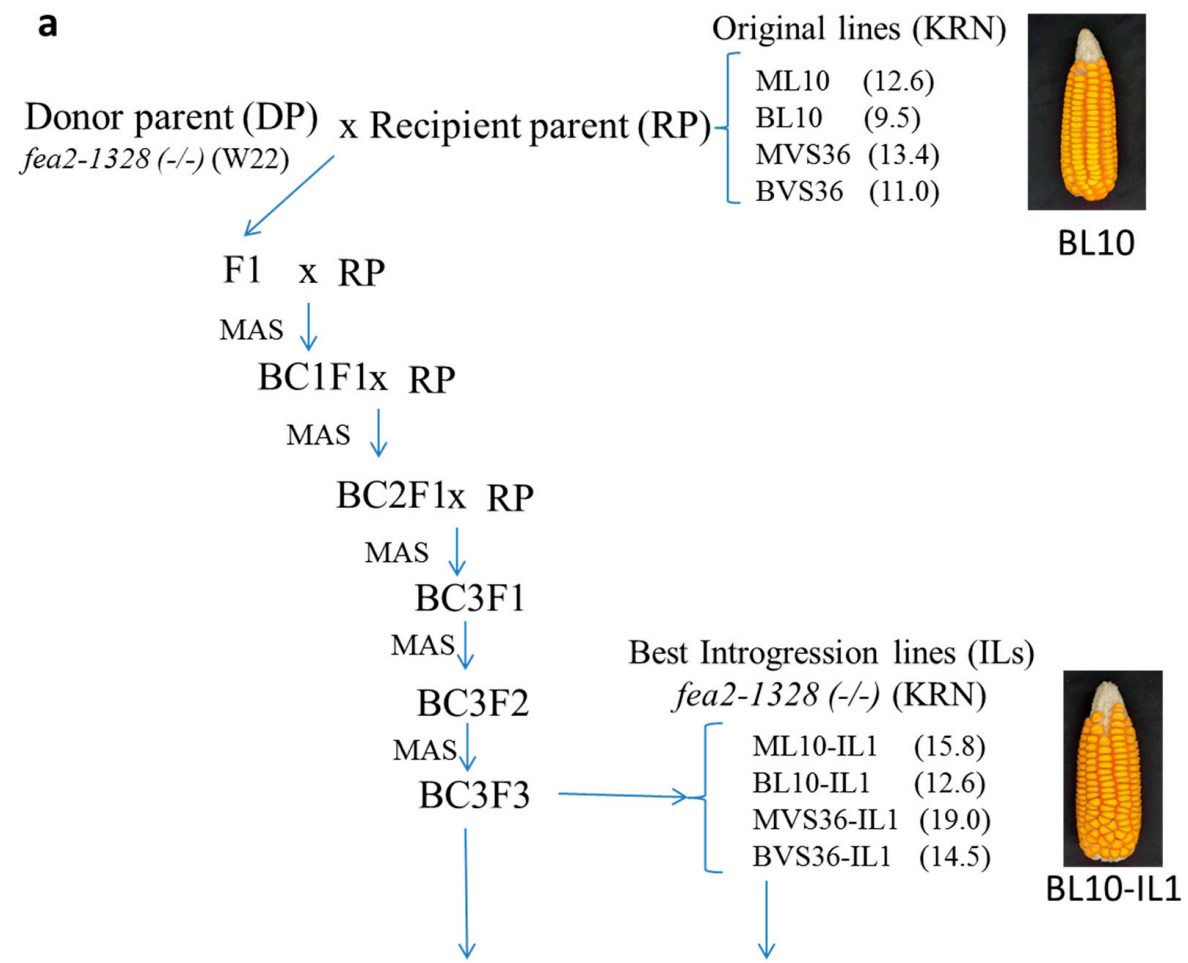

Further selfing, line evaluations

Cross to make hybrids for yield trials

b

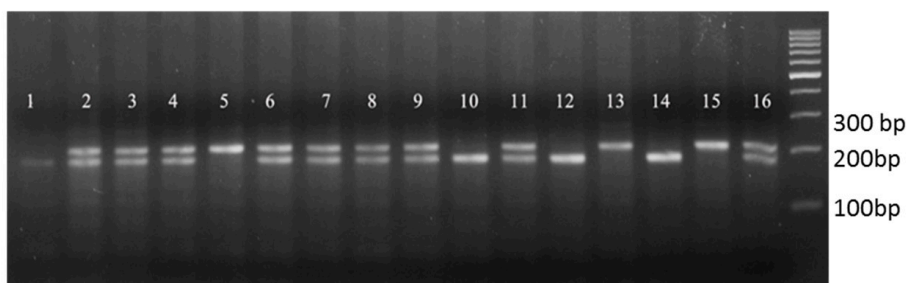

Figure 1. (a) The schematic diagram of developing introgression lines; the averages of kernel row number $(\mathrm{KRN})$ were given in brackets for each line. (b) Genotyping the fea2-1328 alleles with a dCAPs marker. $\mathrm{A} \mathrm{F}_{2}$ family segregating for fea2-1328 was analyzed with the dCAPs marker using oSV1 and oSV2 primers. PCR products were cut with PstI and analyzed on $3 \%$ agarose gel. This marker clearly distinguished three types of genotypes: wild-type plants (lane number 1, 10,12, and 14), homozygous mutant plants (lane number 5, 13, and 15), and heterozygous plants (lane number 2, 3, 4, 6, 7, 8, 9, 11, and 16). 
In each $\mathrm{F}_{1}$ generation of a backcross, i.e., $\mathrm{BC}_{-\mathrm{y}} \mathrm{F}_{1}, 8-20$ plants were genotyped for fea2-1328 alleles. In each $\mathrm{F}_{2}$ generation of a backcross, $\mathrm{BC}_{\mathrm{y}} \mathrm{F}_{2}, 16-40$ plants were genotyped for fea2-1328 alleles. For each $\mathrm{RP}$, at least $2-8$ of the best backcross families were used for the next backcross.

At $\mathrm{BC}_{3} \mathrm{~F}_{6}$, the introgression lines derived from BL10 and ML10 were subjected to genome background checking by SSR (Simple Sequence Repeats) analysis. Two-hundred SSR markers, sequences of which were obtained from www.maizegdb.org, were used to screen for polymorphic markers between BL10, ML10, and DP. Identified polymorphic markers were then used to genotype BL10-IL1 $\left(\mathrm{BC}_{3} \mathrm{~F}_{6}\right)$ and ML10-IL1 $\left(\mathrm{BC}_{3} \mathrm{~F}_{6}\right)$ using pooled DNA of 16 individuals per family. Marker information was provided in Tables S2 and S3.

\subsection{Designing New dCAPs Marker, Genotyping for fea2 Alleles and SSR Analysis}

A new dCAPS marker was re-designed based on the nucleotide sequence of the fea2-1328 alleles published in Bommert, Nagasawa, and Jackson [23]. The information on primers and their sequences for genotyping was listed in the supporting information (Table S1). Primers were ordered from Integrated DNA Technologies Inc. (IDT), Singapore, Republic of Singapore. PCR mix was as follows: $10 \mu \mathrm{L}$ vol reaction; PCR buffer $10 \times-1 \mu \mathrm{L}$; dNTPs $10 \mathrm{mM}-0.25 \mu \mathrm{L}$; Taq -1 unit; forward and reverse primer $10 \mu \mathrm{M}-0.4 \mu \mathrm{L}$ each; DMSO- $1 \mu \mathrm{L}$; DNA template and water to $10 \mu \mathrm{L}$. Thermal conditions were followed for oSV1/oSV2: $94{ }^{\circ} \mathrm{C}$ for $3 \mathrm{~min}$, followed 35 cycles of $\left(94{ }^{\circ} \mathrm{C}: 20 \mathrm{~s}\right.$, annealing temperature: $30 \mathrm{~s}\left(62{ }^{\circ} \mathrm{C}\right.$ for oSV $1+\mathrm{oSV} 2 ; 55^{\circ} \mathrm{C}$ for SSR markers), $72{ }^{\circ} \mathrm{C}: 30 \mathrm{~s}$ ), completed with $72{ }^{\circ} \mathrm{C}$ for $5 \mathrm{~min}$.

For genotyping fea2-1328, PCR products were then digested with restriction enzymes PstI-HF (from New England Biolabs Inc, Ipswich, MA, USA) for $2 \mathrm{~h}$ at $37^{\circ} \mathrm{C}$, then analyzed on the $3 \%$ agarose gel. For SSR analysis, PCR products were analyzed on 6-10\% polyacrylamide gel. Example images of genotyping for fea2-1328 are illustrated in Figure $1 \mathrm{~b}$.

\subsection{Statistical Analysis}

All field data were expressed as mean and standard error of the mean. Chi-square tests and Student's unpaired $t$-tests were applied using Excel, as indicated in the text.

\section{Results}

\subsection{The fea2-1328 Mutant Allele Caused Increases in KRN in All Four Tested Inbreds in $F_{2}$ Generations}

Before further introgression, it is useful to predictat the early generation whether the fea2-1328 mutation expressed in the genetic background of the four inbreds used. Therefore, we analyzed the linkage between the phenotype (KRN) and genotypes in the $\mathrm{F}_{2}$ generations of the crosses between fea-1328 (in W22 background) and the RPs. We found a normal segregation in genotypes, i.e., 1:2:1 ratio, for ML10 and MVS36 ( $p$-values in Chi-square test were 0.54 and 0.35, respectively) but a mild distorted segregation in BL10 and BVS ( $p$-values in Chi-square test were 0.01 and 0.001 , respectively) (Table S4). In three populations with ML10, MVS36, and BVS36, we obtained decent numbers of ears to measure KRN; for the Bl10/fea2-1328 F2 population, we obtained few ears due to poor plant growth and difficulties in pollinations. We measured all ear-producing plants that were homozygous wild-type and mutant and about 15-32 randomly picked plants that were heterozygous (Figure 2). As seen in the histogram in Figure 2, plants that were homozygous for fea2-1328 had a higher percentage of harboring a higher KRN than the plants that were homozygous wild-type. The mean KRN of homozygous mutants was larger than that of wild-type plants for all four inbreds' background, as confirmed by Student's $t$-test, with $p$-values equal to $1.1 \times 10^{-5}, 0.023,0.00054$, and $8.6 \times 10^{-6}$ for the ML10-, BL10-, MVS36-, and BVS36-derived populations, respectively (Table S5). Additionally, statistically comparing the mean KRNs of heterozygous plants to wild-type and homozygous mutant plants revealed that fea2-1328 was likely to be recessive in ML10/W22 and BVS36/W22 $\mathrm{F}_{2}$ with mixed background, as heterozygous is not different to wild-type, but semi-dominant in BL10/W22 and 
MVS36/W22 $\mathrm{F}_{2}$ with mixed background, as heterozygous plants also showed an increase in KRN over wild-type plants, although to a lesser extent than that of mutant plants (Table S5).

ML10/fea2-1328 F2

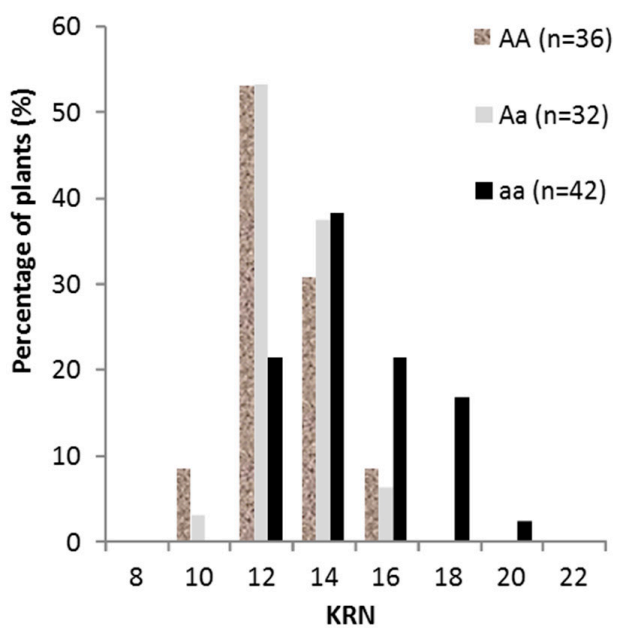

MVS36/fea2-1328 F2

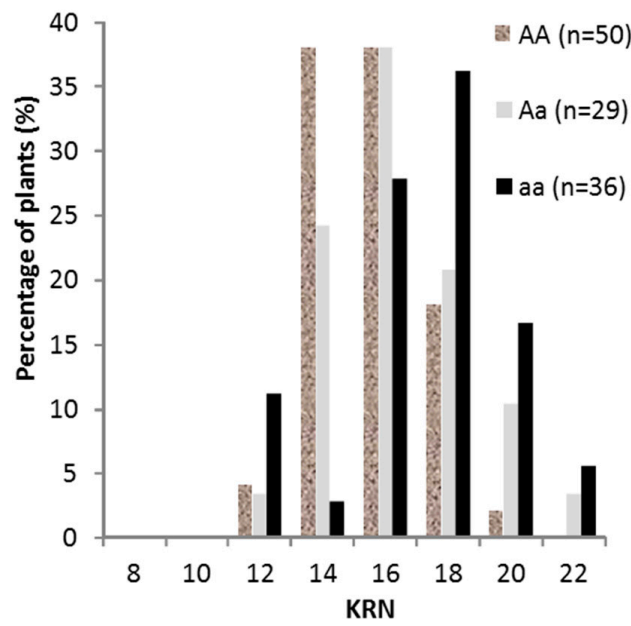

$\mathrm{BL} 10 /$ fea2-1328 F2

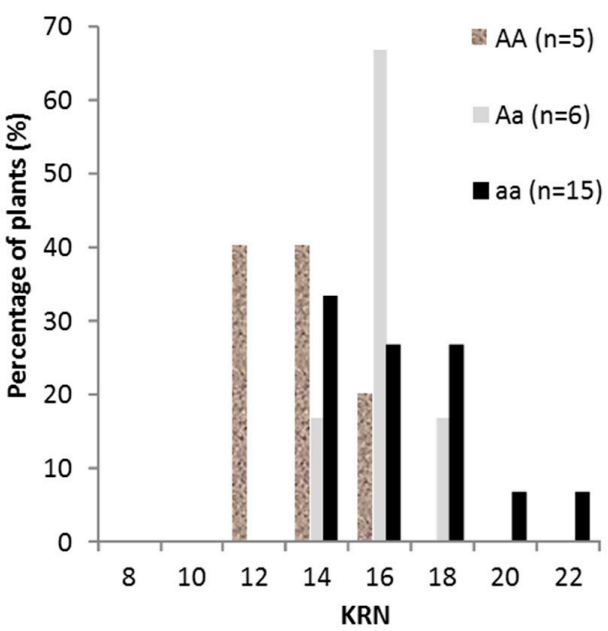

BVS36/fea2-1328 F2

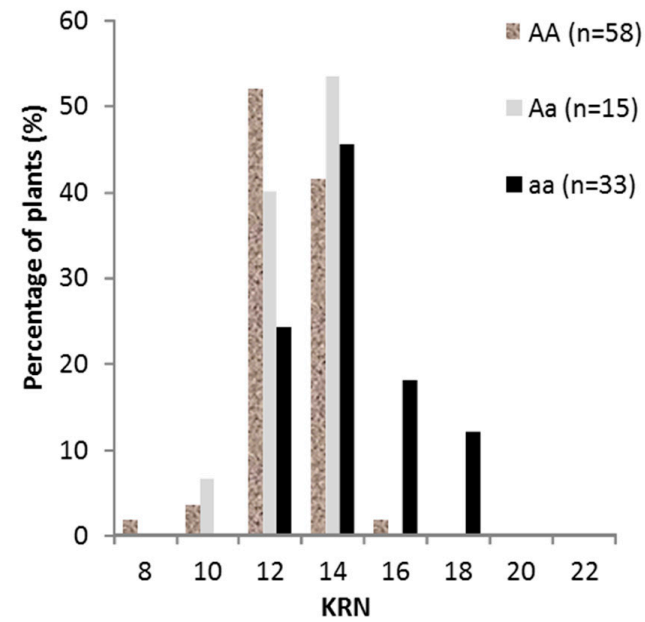

Figure 2. Segregation of phenotypes and genotypes in an $F_{2}$ generation in four recurrent parent backgrounds. AA, Aa, aa: plants that are homozygous wild-type, heterozygous, and homozygous mutant for the fea2-1328 allele, respectively. $n$ : number of plants used for measurements. Genotyped plants were picked randomly for phenotyping; the number of plants indicated did not reflect the segregation ratio of different genotypic classes.

Therefore, fea2-1328 mutation expressed well and caused an increase in $\mathrm{KRN}$ in the $\mathrm{F}_{2}$ generation of all four inbreds and the degree of dominance/recessiveness of fea2-1328 depended on the genetic background used.

\subsection{Marker Assisted Backcrossing}

MABC was carried out with foreground selection for the fea2-1328 marker in each backcross generation, including $\mathrm{F}_{1}, \mathrm{BC}_{1} \mathrm{~F}_{1}, \mathrm{BC}_{2} \mathrm{~F}_{1}, \mathrm{BC}_{3} \mathrm{~F}_{1}, \mathrm{BC}_{3} \mathrm{~F}_{2}$, and $\mathrm{BC}_{3} \mathrm{~F}_{3}$. Several $\mathrm{BC}_{3} \mathrm{~F}_{3}$ introgression lines that were homogeneous and resembled the RPs well were named after their respective RPs, for example, ML10-IL1, ML10-IL2, etc. These were selfed to make $\mathrm{BC}_{3} \mathrm{~F}_{4}$ to $\mathrm{BC}_{3} \mathrm{~F}_{6}$ and crossed to make hybrids which were used for further analysis. 
To determine the introgression region in ILs, we screened all the published SSRs available on www.maizegdb.org around FEA2 and could identify several polymorphic markers between the RP and the DP. Genotyping these markers across DP, $\mathrm{RP}$, and $\mathrm{BC}_{3} \mathrm{~F}_{4}$ ILs (Figure 3 ) revealed the size of introgression region in ILs. BVS36-ILs had recombinations for bnlg1755 and umc2027; the introgression region was therefore equal or less than $35.4 \mathrm{Mb}$, the smallest among all four RPs. BL10-ILs had recombinations for bnlg1755 and bnlg2291, the introgression region was equal or less than 51.3Mb. MVS-ILs and ML10-ILs only had recombinations on one side, which was at marker bnlg1755, 15.3Mb upstream of FEA2. As FEA2 is in bin 4.05, where the centromere lies, limited recombination prevented us from narrowing down the introgression regions.

a

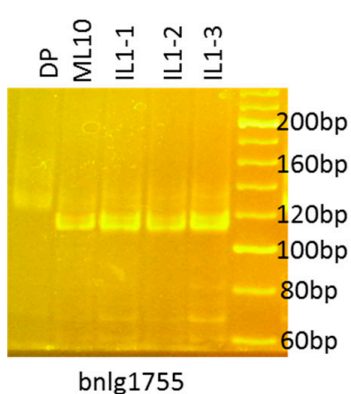

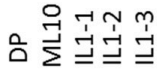

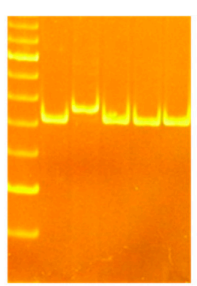

umc1142 b

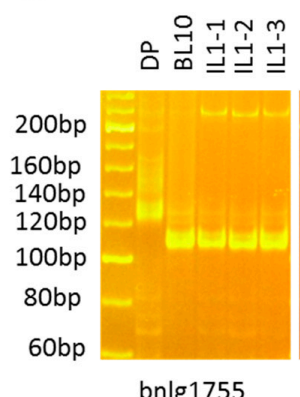

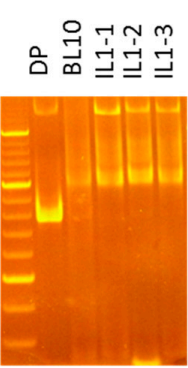

bnlg2291
C
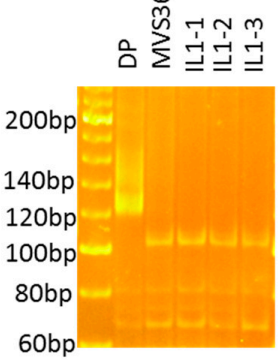

bnlg1755

d
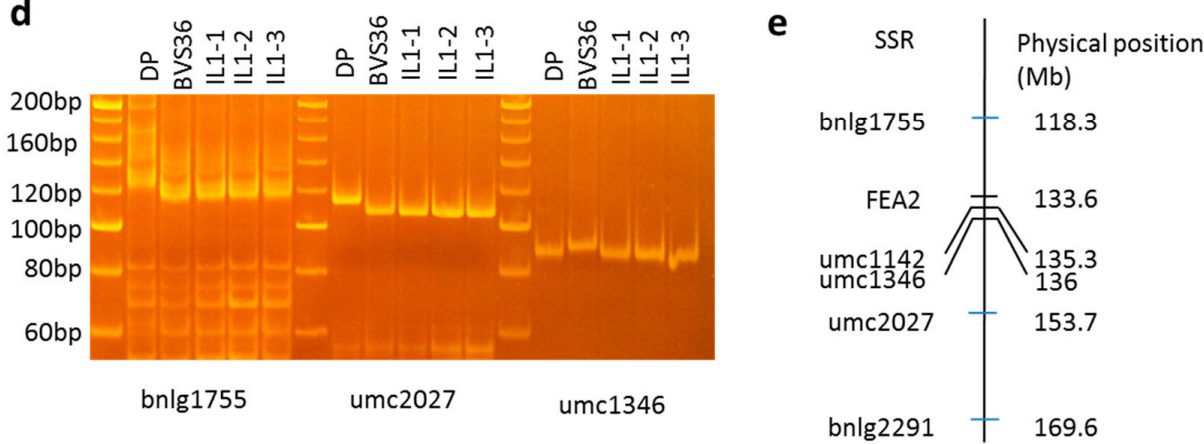

Figure 3. Analysis of the introgression region around the FEA2 loci. SSR (Simple Sequence Repeats) analysis using template DNAs from DP, RP, and corresponding ILs. IL1-1, IL-2, or IL-3 indicated pooled DNA from individuals of the $\mathrm{BC}_{3} \mathrm{~F}_{4}$ family 1, 2, or 3. (a) Polymorphic SSRs between DP and ML10. (b) Polymorphic SSRs between DP and BL10. (c) Polymorphic SSRs between DP and MVS36. (d) Polymorphic SSRs between DP and BVS36. Ladders are O'RangeRuler 20 bp DNA Ladders from Thermo Fisher. (e) Physical map of the SSRs that are close to FEA2.

To estimate how much of the genome background was recovered in ILs in BC3, SSR analysis was performed. Two-hundred SSR markers spreading across ten chromosomes of maize were screened and 28 markers were identified to be polymorphic between ML10 and DP (Table S2); the figure for BL10 was 17 (Table S3). In ML10, apart from chromosome 10 where only one polymorphic marker was found, the SSR markers spread largely, even in other chromosomes (Figure S1 and Table S2). In BL10, only one polymorphic marker was found on chromosome 8 and 10 and no polymorphic markers were found on chromosome 7 and 9 (Figure S2 and Table S3). SSR analysis showed 15 out of the 17 markers and 26 out of the 28 markers were recovered in IL for BL10-IL1 (BC3F6) and ML10-IL1 (BC3F6), respectively (Figures S1 and S2). These results support the high recovery of background genome in our ILs and provide information for further backcrosses and phenotypic analysis. 
3.3. The fea2-1328 Allele Caused an Increase in KRN in most ILs in BC3F3 but also Affected Other Agronomic Traits

We thoroughly compared KRN and other agronomic traits between the ILs and their corresponding RPs. The comparison was carried out in $\mathrm{BC}_{3} \mathrm{~F}_{3}$ generations in order to early select the best lines for further backcrosses or selfing. For each RP, one to three of the best homozygous lines were selected based on their resemblance to the RP and used for detailed analysis and measurements.

In the $\mathrm{BC}_{3} \mathrm{~F}_{3}$ families, the plants were homogeneous (Figure 4). Major agronomic traits, including plant height (PH), ear height (EH) and tassel branch number (TBN), ear length (EL), ear diameter (ED), 1000 seed weight (SW), kernel row number (KRN), and number of kernel per row (KRP) between RPs and (ILs), were compared as shown in Figure 4 and Table 1. It was apparent that KRN significantly increased in six out of seven ILs (Table 1). The strongest increase was observed in MVS36-ILs of 5.6 rows (averaged two $\mathrm{BC}_{3}$ lines), followed by 4.1 rows in ML10-ILs (averaged two $\mathrm{BC}_{3}$ lines), 3.1 rows in BL10-ILs, and the weakest increase was in BVS36-ILs of 1.64 rows (averaged two $\mathrm{BC}_{3}$ lines) compared to respective RPs.

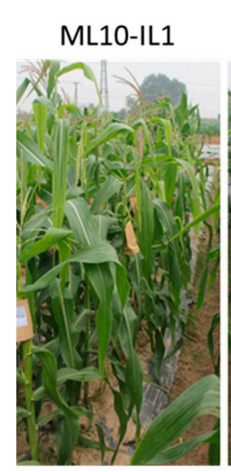

MVS36-IL1

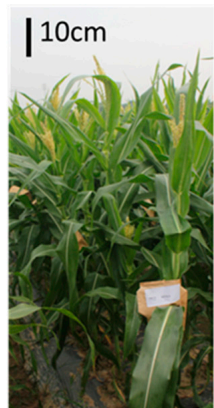

ML10

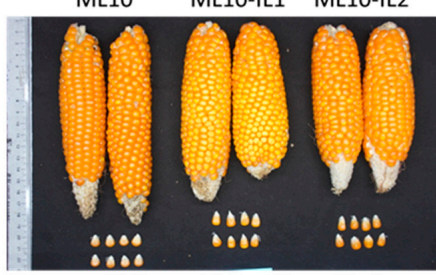

MVS36 MVS36-IL1 MVS36-IL2

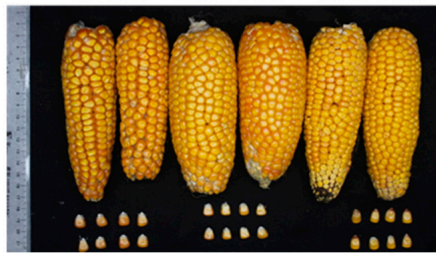

BL10-IL1

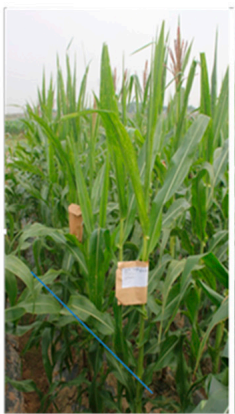

BVS36-IL1

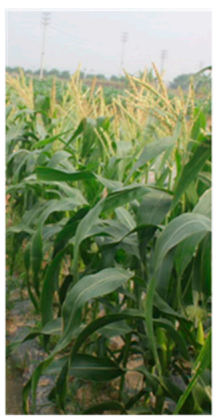

BL10

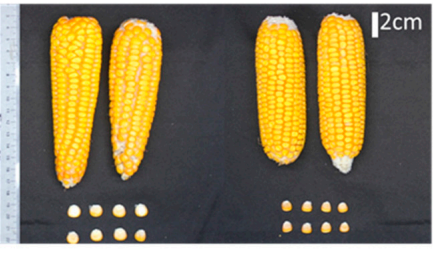

BVS36 BVS36-IL1 BVS36-IL2

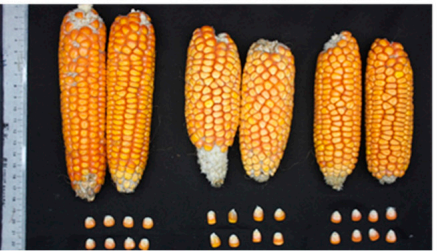

Figure 4. Plants and ears of introgression lines that were homozygous for fea2-1328 at the $\mathrm{BC}_{3} \mathrm{~F}_{3}$ generation and the corresponding recurrent parents. 
Table 1. Measurements of agronomic traits and yield of introgression lines and their corresponding recurrent parents.

\begin{tabular}{|c|c|c|c|c|c|c|c|c|c|c|c|c|c|c|c|c|c|c|c|}
\hline \multirow{2}{*}{ Lines } & \multicolumn{2}{|c|}{ Plant Height } & \multirow{2}{*}{$\begin{array}{l}\text { Ear Height } \\
\mathrm{cm}\end{array}$} & \multicolumn{3}{|c|}{ Tassel Branch Number } & \multicolumn{2}{|c|}{ Ear Length } & \multirow{2}{*}{$\begin{array}{l}\text { Diameter } \\
\mathrm{cm}\end{array}$} & \multicolumn{3}{|c|}{ Kernel Row Number } & \multicolumn{2}{|c|}{ Kernel per Row } & \multicolumn{2}{|c|}{ Weight of 1000 Seeds } & \multirow{2}{*}{$\begin{array}{r}\text { Yield } \\
\times 100 \mathrm{~kg} / \mathrm{ha}\end{array}$} & \multirow{2}{*}{\multicolumn{2}{|c|}{ Ratio $^{n}$}} \\
\hline & $\mathrm{cm}$ & Ratio & & Ratio & & Ratio & $\mathrm{cm}$ & Ratio & & Ratio & Row & Ratio & Kernel & Ratio & o Gram & Ratio & & & \\
\hline ML10 & $155 \pm 1.9$ & 1.00 & $54.1 \pm 1.7$ & 1.00 & $8.5 \pm 0.7$ & 1.00 & $13.0 \pm 0.4$ & 1.00 & $2.9 \pm 0.1$ & 1.00 & $11.6 \pm 0.3$ & 1.00 & $24.2 \pm 0.8$ & 1.00 & $225 \pm 2.0$ & 1.00 & 31.5 & 1.00 & 16 \\
\hline ML10-IL1 & $143^{* *} \pm 2.2$ & 0.92 & $48.4 * \pm 1.4$ & 0.90 & $9.1 \pm 0.4$ & 1.07 & $10.8 * * \pm 0.2$ & 0.83 & $3.4 * * \pm 0.1$ & 1.17 & $15.8 * * \pm 0.3$ & 1.36 & $21.3 * \pm 0.7$ & 0.88 & $201 * \pm 1.8$ & 0.90 & 31.0 & 0.98 & 30 \\
\hline ML10-IL2 & $143^{* *} \pm 2.1$ & 0.92 & $43.3^{* *} \pm 1.6$ & 0.80 & $7.7 \pm$ & 0.90 & $10.6^{* *} \pm 0.2$ & 0.81 & $3.3^{* *} \pm 0.1$ & 1.11 & $15.5^{* *} \pm 0.3$ & 1.33 & $22.4 \pm 0.6$ & 0.92 & $195^{* *} \pm 1.5$ & 0.87 & 30.0 & 0.95 & 27 \\
\hline BL10 & $165 \pm 3.7$ & 1.00 & $60.4 \pm 1.6$ & 1.00 & $15.3 \pm 3.4$ & 1.00 & $9.6 \pm 0.2$ & 1.00 & $3.0 \pm 0.0$ & 1.00 & $9.5 \pm 0.2$ & 1.00 & $24.8 \pm 0.7$ & 1.00 & $156 \pm 0.8$ & 1.00 & 21.0 & 1.00 & 26 \\
\hline BL10-IL1 & $168 \pm 2.8$ & 1.02 & $58.8 \pm 1.5$ & 0.97 & $14.2 \pm 0.4$ & & & 0.99 & & 1.02 & $12.6 * * \pm 0.4$ & & $24.0 \pm 1.1$ & 0.97 & & 0.94 & 18.5 & 0.88 & 24 \\
\hline MVS36 & $146 \pm$ & 1.00 & $62.9 \pm 1.3$ & 1.00 & & & & & & 1.00 & & & & 1.00 & & & & 1.00 & 29 \\
\hline MVS36-IL1 & $140 \pm 2.4$ & 0.96 & $63.6 \pm 1.4$ & 1.01 & $13.1 \pm 0.3$ & 1. & $10.2 \pm 0.5$ & 1.05 & $4.1^{* *} \pm 0.1$ & 1.20 & $19.0^{* *} \pm 0.5$ & 1.42 & $18.6 \pm 0.9$ & 0.92 & $175^{* *} \pm 2.5$ & 0.75 & 31.5 & 1.04 & 28 \\
\hline MVS36-IL2 & $153 \pm 3.0$ & 1.05 & & 0.96 & & & & 1.03 & $3.8 * * \pm 0.1$ & 1.10 & $19.0 * * \pm 0.4$ & & & 1.07 & $151^{* *} \pm 2.2$ & 0.65 & 29.0 & 0.96 & 28 \\
\hline BVS36 & $135 \pm 1.5$ & 1.00 & $36.3 \pm 1.1$ & 1.00 & $8.8 \pm 0$ & 1. & $10.6 \pm 0.4$ & 1.00 & $3.3 \pm 0.0$ & 1.00 & $11.1 \pm 0.3$ & 1.00 & $20.8 \pm 1.0$ & 1.00 & $228 \pm 0.5$ & 1.00 & 20.4 & 1.00 & 23 \\
\hline BVS36-IL1 & $125^{* *} \pm 2.2$ & 0.93 & $26.7^{* *} \pm 0.8$ & 0.74 & $7.0^{* *} \pm 0.2$ & 0.79 & $8.6^{* *} \pm 0.4$ & 0.81 & $3.9^{* *} \pm 0.1$ & 1.16 & $14.5^{*} \pm 0.4$ & 1.31 & $14.0^{* *} \pm 0.9$ & 0.67 & $281 * * \pm 1.5$ & 1.23 & 22.4 & 1.10 & 24 \\
\hline BVS36-IL2 & $131 \pm 2.1$ & 0.97 & $35.1 \pm 1.1$ & 0.97 & $4.5^{* *} \pm 0.3$ & 0.52 & $8.7^{* *} \pm 0.2$ & 0.81 & $3.2 \pm 0.1$ & 0.97 & $11.6 \pm 0.3$ & 1.04 & $16.6^{* *} \pm 0.6$ & 0.80 & $228 \pm 1.8$ & 1.00 & 20.6 & 1.01 & 26 \\
\hline
\end{tabular}

Mean value \pm standard error of the mean (s.e.m) is shown in real value units; the ratio was calculated over the value of the corresponding parent. $n-$ least number of plants used for the measurements except for the weight of 1000 seeds $(n \geq 3) . * * *$ indicate significantly different compared to the recurrent parent (Student's $t$-test, $p$-value $<0.05$ and 0.01 , respectively). IL-introgression line. 
Several agronomic traits differed between RP and ILs, and interestingly, the degree of differences varies among inbreds, suggesting other previously undescribed functions of $F E A 2$ and a complex interaction between FEA2 and genetic backgrounds in these different heterotic group parents. For example, TBN was remarkably reduced by $21 \%$ and $48 \%$ in only BVS36-IL1 and BVS36-IL2 compared to BVS36, but varied only slightly $(<10 \%)$ and not significantly between other ILs and their corresponding RPs. The EL showed an approximately 20\% reduction in BVS36-Ils and ML10-ILs, but was almost unchanged in MVS-ILs and BL10-ILs compared to the RPs. PH was reduced slightly by $8 \%$ in both ML10 ILs and 7\% in BVS36 IL1, but it was not significantly different in the MVS36 ILs and BL10 ILs as compared to RPs. The averaged SW was reduced by approximately $10 \%$ in ML10 and 30\% in MVS36 background, increased 23\% in BVS36-IL1 but did not differ significantly for BL10. As a combination of changes in KRN, SW, and EL, the yield of ILs however did not differ significantly from the RPs. Therefore, it was concluded that despite an over 30\% increase in KRN in six out of seven ILs, the yield of these ILs per se did not increase.

\subsection{Potential of Using fea2-1328 to Increase the Yield of Hybrids}

Due to heterosis, hybrids may have more photosynthetic material to fill the extra seeds generated by increased KRN, hence the effect of fea2-1328 on yield may be different between inbreds and hybrids. To further examine if fea2-1328 can possibly increase the KRN and yield of hybrids, we made crosses between parental ILs of LVN10 hybrid and conducted a yield trial. We have prioritized the hybrid trial on LVN10 due to LVN10 being a more demanded variety in Vietnam. A yield trial was conducted in field conditions across four cropping seasons and three locations, which, respectively, represent the plateau (Thai Binh, Ha Noi) and mountainous (Son La) growing areas of LVN10 maize variety (Figure 5, Table 2). The introgressed hybrid (LVN10 fea2-/-) seeds were made by crossing ML10-IL1 (BC3Fx) and BL10-IL1 (BC3Fx), with $x$ referring to the generation of selfing. The LVN10 fea2-/- hybrid seeds used in the Thai Binh Spring cropping season in 2017 were ML10-IL1 $\left(\mathrm{BC}_{3} \mathrm{~F}_{3}\right)$ crossed by BL10-IL1 $\left(\mathrm{BC}_{3} \mathrm{~F}_{3}\right)$. The LVN10 fea2-/- seeds used in Thai Binh in Autumn 2017 and Son La in Summer 2018 were ML10-IL1 $\left(\mathrm{BC}_{3} \mathrm{~F}_{4}\right) \times$ BL10-IL1 $\left(\mathrm{BC}_{3} \mathrm{~F}_{4}\right)$. The LVN10 fea2-/- seeds used in Ha Noi and Thai Binh in Spring 2020 were ML10-IL1 $\left(\mathrm{BC}_{3} \mathrm{~F}_{6}\right) \times$ BL10-IL1 $\left(\mathrm{BC}_{3} \mathrm{~F}_{6}\right)$. All the introgressed hybrids were homozygous for fea2-1328. As shown in Figure 5 and Table 2, introgressed LVN10 (LVN10 fea2-/-) had on average 1.1 to 3.6 KRNs more than original LVN10. Interestingly, opposite to the results found in its maternal inbred ML10-ILs, the seed weights of LVN10 fea2-/- were not reduced compared to the wild-type. Yield was increased by $8 \%$ to $28 \%$ depending on generations, testing locations, and seasons. The other agronomic traits $(\mathrm{PH}$, $\mathrm{EH}, \mathrm{EL}, \mathrm{TBN}$ ) of the introgressed hybrid were largely similar to that of the original hybrid (Figure $5 \mathrm{~b}$, Table 2). These results strongly suggested that fea2-1328 can increase KRN and yield in maize hybrid LVN10, keeping other agronomic traits mostly unaffected. 

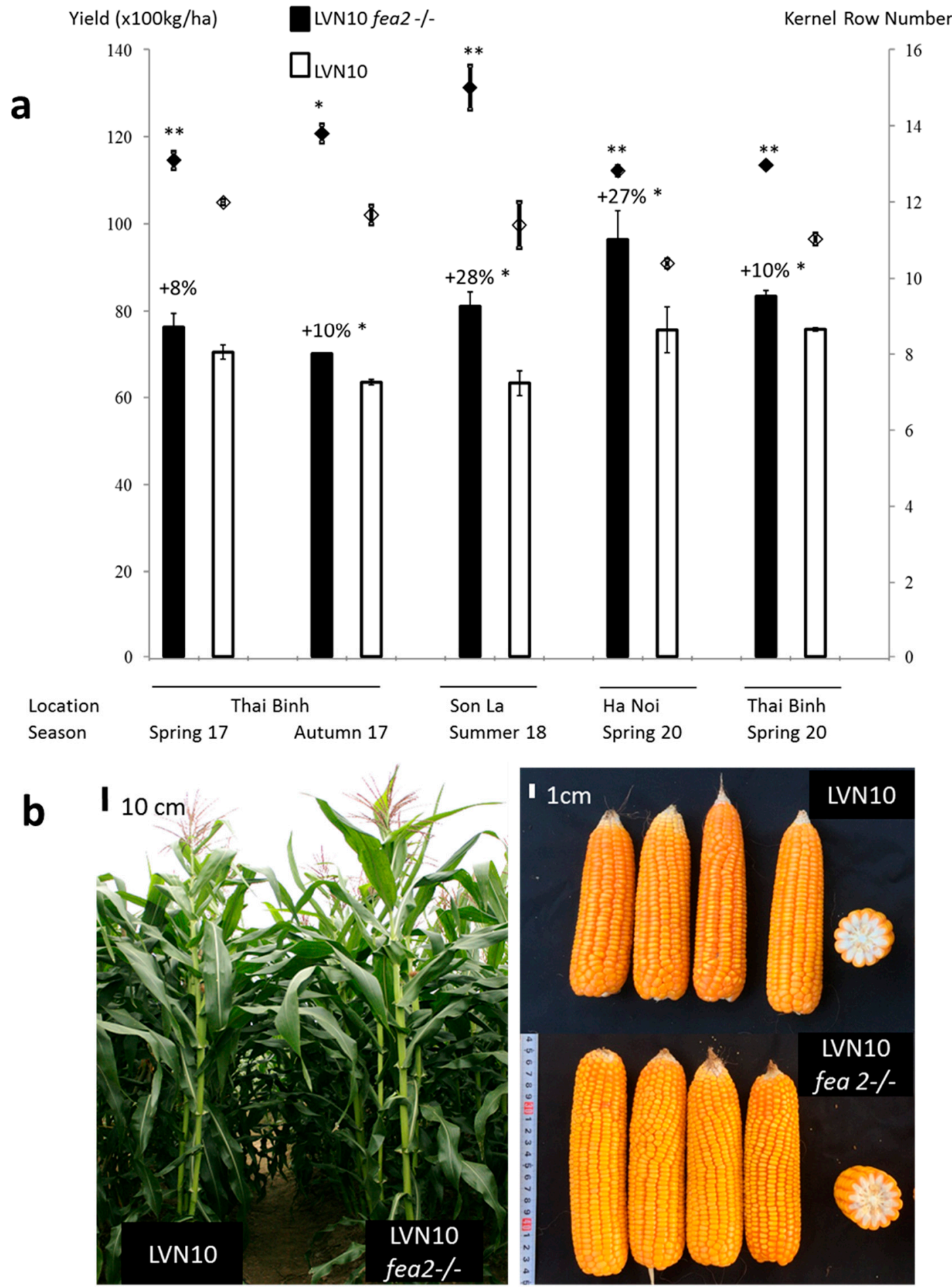

Figure 5. Yield trial of the original LVN10 hybrid and the LVN10 hybrid with fea2-1328 introgressed (LVN10 fea2-/-). (a) Yield trial data. Columns showed yields and diamond dots showed KRNs. Unfilled symbols are LVN10 control; black-filled symbols are LVN10 fea2-/-. Percentages of yield increase over original LVN10 were showed on top of the columns. Yield trials were carried out in three different locations and four seasons as shown. ${ }^{*}$ and ${ }^{* *}$ symbols indicate significantly different by Student's unpaired $t$-test at $p<0.05$ and $p<0.01$, respectively. Error bars are s.e.m, $n \geq 3$ for yield; $n \geq 20$ for KRN. (b) Example images of plants and ears of LVN10 and LVN10 fea2-/- taken in Son La in summer 2018. 
Table 2. Measurements of agronomic traits and yield of introgressed hybrid (LVN10 fea2-/-) and the original hybrids (LVN10) in multiple locations and seasons.

\begin{tabular}{|c|c|c|c|c|c|c|c|c|c|c|c|c|c|c|c|c|c|c|c|}
\hline \multirow{2}{*}{ Location-Season- Hybrid } & \multicolumn{2}{|c|}{ Plant Height } & \multirow{2}{*}{$\begin{array}{l}\text { Ear Height } \\
\mathrm{cm}\end{array}$} & \multicolumn{3}{|c|}{ Tassel Branch Number } & \multicolumn{2}{|l|}{ Ear Length } & \multirow{2}{*}{$\begin{array}{l}\text { Diameter } \\
\mathrm{cm}\end{array}$} & \multicolumn{3}{|c|}{ Kernel Row Number } & \multicolumn{2}{|c|}{ Kernel per Row } & \multicolumn{2}{|c|}{ Weight of 1000 Seeds } & \multirow{2}{*}{$\begin{array}{r}\text { Yield } \\
\times 100 \mathrm{~kg} / \mathrm{ha}\end{array}$} & \multirow{2}{*}{\multicolumn{2}{|c|}{ Ratio ${ }^{n}$}} \\
\hline & $\mathrm{cm}$ & Ratio & & Ratio & & Ratio & $\mathrm{cm}$ & Ratio & & Ratio & Row & Ratio & Kernel & Ratio & Gram & Ratio & & & \\
\hline TB-Au17-LVN10 & $213 \pm 1.2$ & 1.00 & $114.3 \pm 1.5$ & 1.00 & N.D. & - & $14.3 \pm 0.1$ & 1.00 & $4.0 \pm 0.2$ & 1.00 & $11.7 \pm 0.2$ & 1.00 & $30.6 \pm 1.8$ & 1.00 & $255 \pm 0.5$ & 1.00 & $63.5 \pm 0.6$ & 1.00 & \\
\hline TB-Au17- & & 1.02 & & & & - & & & & & & & & & & & & & \\
\hline SL-Su18- LVN & $196 \pm 3.2$ & 1.00 & $111.8 \pm 3.2$ & 1.00 & N.D. & - & $16.5 \pm 0.6$ & 1.00 & $4.7 \pm 0.1$ & 1.00 & $11.4 \pm 0.6$ & 1.00 & $31.4 \pm 2.0$ & 1.00 & $300 \pm 1.8$ & 1.00 & $63.3 \pm 2.8$ & 1.00 & 20 \\
\hline SL-Su18- LVN10 & $209 * \pm 1.5$ & 1.06 & $116.4 \pm 2.2$ & 1.04 & N.D. & & & 1.02 & $5.0 * \pm 0.1$ & 1.07 & $15.0^{* *} \pm 0.6$ & 1.32 & $39.8 * * \pm 1.6$ & 1.27 & & 0.97 & $81.1 * \pm 3.3$ & 1.28 & 20 \\
\hline HN-Sp20-LVN1 & & 1.00 & $133.5 \pm 1.3$ & 1.00 & $15.2 \pm 0.2$ & 1.00 & $17.1 \pm 0.1$ & 1.00 & $3.9 \pm 0.02$ & 1.00 & $10.4 \pm 0.1$ & 1.00 & $33.6 \pm 0.6$ & 1.00 & & 1.00 & $75.7 \pm 4.1$ & 1.00 & 0 \\
\hline HN-Sp20-LVN10 fea2-- & $244^{* *} \pm 1.0$ & 0.961 & $122.0^{* *} \pm 0.9$ & 0.91 & $13.1^{* *} \pm 0.2$ & 0.86 & $19.0^{* *} \pm 0.1$ & 1.11 & $4.2^{* *} \pm 0.03$ & 1.07 & $12.8^{* *} \pm 0.1$ & 1.23 & $33.0 \pm 0.5$ & 0.98 & $267 \pm 4.3$ & 1.01 & $96.4 * \pm 3.9$ & 1.27 & \\
\hline TB-Sp20- LVN10 & $208 \pm 2.3$ & 1.00 & $119.4 \pm 1.9$ & 1.00 & $10.0 \pm 0.3$ & 1.00 & $15.5 \pm 0.1$ & 1.00 & $4.1 \pm 0.02$ & 1.00 & $11.0 \pm 0.1$ & 1.00 & $33.5 \pm 0.7$ & 1.00 & $273 \pm 4.1$ & 1.00 & $75.7 \pm 1.7$ & 1.00 & 40 \\
\hline TB-Sp20- LVN10 fea2-- & $212 * \pm 0.8$ & 1.02 & $117.1 \pm 0.6$ & 0.98 & $9.1 * * \pm 0.2$ & 0.91 & $15.0^{* *} \pm 0.1$ & 0.97 & $4.3^{* *} \pm 0.01$ & 1.05 & $13.0^{* *} \pm 0.1$ & 1.18 & $32.9 \pm 0.3$ & 0.98 & $280 \pm 3.4$ & 1.02 & $83.4 * \pm 1.1$ & 1.10 & 40 \\
\hline
\end{tabular}

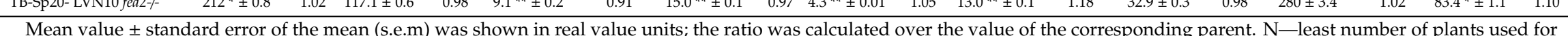

the measurements except for the weight of 1000 seeds $(n \geq 3)$, for yield $n \geq 3$. N.D.—not determined. *** indicate significantly different compared to the original hybrid (Student's $t$-test, $p$-value $<0.05$ and 0.01, respectively). Yield trial place, and season: TB-Au17-Thai Binh, Autumn 2017; SL-Su18—Son La, Summer 2018; HN-Sp20—Ha Noi, Spring 2020; TB-Sp20—Thai Binh, Spring 2020. 


\section{Discussion}

In this study, we introgressed a weak allele of $F E A 2$, fea2-1328, into four Vietnamese elite inbreds and measured phenotype and yield in the ILs as well as the resulting hybrid of one pair of inbreds. Our results indicated that fea2-1328 can increase from 2 to up to 6 more kernel rows without causing fasciation in all four genetic backgrounds tested, as well as in the LVN10 hybrid. fea2-1328 improved both the low KRN inbred (like ML10 and BL10, BVS36 with 10-12 KRN) and high KRN inbred (like MVS36 with $14 \mathrm{KRN}$ ). These results have reconfirmed the effect of weak fea2-1328 alleles on KRN as suggested by Bommert, Nagasawa, and Jackson [23] and provided the additional information that this effect can express well in other maize backgrounds with different KRN.

Besides affecting KRN, our detailed characterization of ILs of several genetic backgrounds showed new findings on the potential effect of fea2-1328 and/or its linkage drag on other traits, notably TBN, PH, EL, and SW. Those effects were found to be dependent on the genetic background of the RP. This not only provides important information for the breeders, but also a basis for further gene function study. For example, fea2-1328 causes a strong reduction in TBN in the BVS36 background; reduction in TBN can be a target for breeders to divert assimilates to ears rather than tassel for yield improvement. These differences between ILs and their corresponding RPs detailed in Table 1 can be explained by at least three factors: the effect of fea2-1328 itself, the linked loci to FEA2, i.e., the linkage drag, and the other unlinked residual donor genetics remaining in the ILs. Our data suggest fea2-1328 itself and/or the linked loci are the main causes because of several observations. Firstly, the reduction in EL, $\mathrm{PH}$, and SW can be observed in multiple ILs of the same RP background and is also observed in several RP backgrounds, suggesting it is likely that fea2 and/or its tightly linked loci rather than the unlinked residual donor loci, which was caused by incomplete backcross, are responsible. Because of limited recombination around $F E A 2$, which is in the centromeric region, our results could not discriminate between the effect of fea2-1328 itself or the linked loci. Our SSR analysis revealed that the introgressed linkage groups were reasonably large (over $35 \mathrm{Mb}$ ), hence potentially having many genes that contribute to the differences between ILs and RPs. It is noteworthy to mention that our data supported the complex interaction between fea2-1328 and the genetic background. For example, the deleterious effect (on $\mathrm{PH}$, EL, SW) of fea2-1328 seemed modest in the BL10 background.

The potentially deleterious effect of fea2-1328 and its linkage drag on the PH, EL, and SW were not described in the previous report [23] and may have important implications for further use of this allele in maize breeding. When introgressing fea2-1328 alleles to improve the yield of ILs or at least keep yield unaffected, breeders must consider background genetics' effect and keep the balance between KRN increase, plant vigor, and yield during backcrossing rather than selection based solely on the highest percentage of genomic RP recovery or ILs with the highest KRN increase.

Our results also revealed interesting insights into the different effects of fea2-1328 in inbreds compared to hybrids. Clearly, the deleterious effects that fea2-1328 had in the maternal parent ML10-IL1 (on TBN, PH, SW, and EL) were largely lifted in hybrids. We propose that the heterosis and higher photosynthesis capacity of introgressed hybrid plants created enough biomass to fill the extra kernels created by increased KRN, whereas the maternal inbred parents may not have had enough biomass to do this. It has been shown that there is a close relationship among kernel number, kernel weight, and sink/source ratio, which was controlled by the ability of plants to partition the assimilates into kernels during the grain-filling period [34-36]. Our results suggest even if the yield does not increase in both introgressed parental inbreds per se, the resulting introgressed hybrid may still have increased yield.

When using MABC targeting a fully recessive locus, making both parents carry the same locus may reduce the heterosis of hybrids. This concern is particularly relevant in the case of $F E A 2$, where the pericentromeric position of $F E A 2$ can lead to large introgression size, which, when made homozygous in hybrids, could cause reduced heterosis. It was previously proposed that genes in centromeric and pericentromeric regions can be one important contributing factor to heterosis [37-39]. In this study, introgressed LVN10 fea2-/- retained full heterosis and had a higher yield than the original 
LVN10. This result removes the doubt about reduced heterosis caused by FEA2-linked pericentromeric homozygosity in introgressed hybrids, at least in the LVN10 case. Our study presented here may be useful when one is considering MABC of pericentromeric recessive locus in heterosis-sensitive crops.

The potential of using mutations in meristem size regulators of the CLV-WUS signaling pathway to improve fruit size, fruit number, and yield have been shown in several other crop species [40]. In tomato (Solanum lycopersicum), fasciated and branched (fab), a mutation in a homolog of CLV1 [41]; locule number (lc), a mutation in a homolog of WUSCHEL [42]; fasciated (fas), a mutation in a homolog of CLV3 [41]; and excessive number of floral organs (eno), a mutation in an upstream regulator of WUSCHEL [43], were all shown to cause enlarged fruits and higher locule numbers. Natural mutations in these genes have played central roles in domestication and breeding, and have contributed to the diversification of fruit size and shape in tomato [44-46]. Point mutation in the CLV3 homolog in field mustard (Brassica rapa) caused an increased number of locules in siliques and had the potential to increase seed yield [47]. In rice (Oryza sativa), CLV1 and CLV3 homologs were first cloned from mutants with higher floral organ numbers: fon1-1 and fon4-1, respectively [48-50]. These alleles did not produce more flower/seeds per panicle; however, an allelic mutant of FON1 called multi grain 1 ( $m g 1)$ [51], and an allelic mutant of FON4 called twin-grain 1 (tg1) [52], were later discovered and were both reported to have two florets in the spikelet, hence having the potential to increase grain number per panicle.

Future directions are to expand this study using weak alleles of other meristem size regulators like TD1 [53], FEA3 [54], FEA4 [55], CT2 [56], and ZmCLE7 [32,57]. It is of interest and agronomic importance to see how much KRN can increase without affecting other traits, and how much yield can be increased in hybrid using stacks of favorable KRN genes/QTLs. Furthermore, one can use CRISPR-Cas9 to generate weak alleles in meristem size regulators and test their effects on the yield of inbred per se and hybrid [57,58].

\section{Conclusions}

This study was the first report to demonstrate that fea2-1328 can be utilized to improve KRN and yield of an existing hybrid and provide a previously undescribed potential function of FEA2 on TBN, $\mathrm{PH}$, and EL. Our yield-improved tropical maize germplasms are freely available to breeders for their breeding programs. This knowledge can be applied to other elite maize hybrids and provides a simple, non-transgenic (GMO) approach to improve the yield of an existing variety by $8-28 \%$.

Supplementary Materials: The following are available online at http://www.mdpi.com/2073-4395/10/11/1774/s1, Table S1: Primers used to genotype fea2-1328 and analyze the introgression region; Table S2: SSR markers that are polymorphic between the ML10 (RP) and fea2-1328 -/- (W22) (DP); Table S3: SSR markers that are polymorphic between the BL10 (RP) and fea2-1328 -/- (W22) (DP); Table S4: Genotypic seggregation ratio analysis of F2 families of RP/DP; Table S5: The comparision of KRN means of different groups of genotypes in F2 population of RP/RP, Figure S1: Genome background analysis of ML10-IL1 $\left(\mathrm{BC}_{3} \mathrm{~F}_{6}\right)$ with SSR markers; Figure S2: Genome background analysis of BL10-IL1 $\left(\mathrm{BC}_{3} \mathrm{~F}_{6}\right)$ with SSR markers.

Author Contributions: Designed the research S.L.V., K.H.T., B.M.T.; conducted the experiments S.L.V., K.H.T., Q.H.T., N.H.B., T.T.T., K.Q.L., N.T.T.T., L.T.N., D.T.N.N., B.D.V., D.T.T.Q., D.T.N., H.T.N., C.C.D.; analyzed the data and wrote the manuscript: S.L.V., K.H.T. and T.D.K. All authors have read and agreed to the published version of the manuscript.

Funding: This project was supported by funding from The Biotechnology Program for Agriculture-Aquaculture, Ministry of Agriculture and Rural Development, Vietnam and The National Foundation for Science and Technology Development (Vietnam) NAFOSTED under grant number 106-NN.01-2014.48.

Acknowledgments: We would like to thank Professor David Jackson for his gift of the original donor line fea2-1328 (W22) and for his reviews and comments on the manuscript.

Conflicts of Interest: The authors declare no conflict of interest.

\section{References}

1. Shiferaw, B.; Prasanna, B.M.; Hellin, J.; Bänziger, M. Crops that feed the world 6. Past successes and future challenges to the role played by maize in global food security. Food Secur. 2011, 3, 307. [CrossRef] 
2. Alexandratos, N.; Bruinsma, J. World Agriculture towards 2030/2050: The 2012 Revision; ESA Working paper No. 12-03; FAO: Rome, Italy, 2012; p. 122.

3. Ray, D.K.; Gerber, J.S.; MacDonald, G.K.; West, P.C. Climate variation explains a third of global crop yield variability. Nat. Commun. 2015, 6, 1-9. [CrossRef] [PubMed]

4. Ureta, C.; González, E.J.; Espinosa, A.; Trueba, A.; Piñeyro-Nelson, A.; Álvarez-Buylla, E.R. Maize yield in Mexico under climate change. Agric. Syst. 2020, 177, 102697. [CrossRef]

5. Rosegrant, M.R.; Ringler, C.; Sulser, T.B.; Ewing, M.; Palazzo, A.; Zhu, T.; Nelson, G.C.; Koo, J.; Robertson, R.; Msangi, S.; et al. Agriculture and Food Security under Global Change: Prospects for 2025/2050; Internaltional Food Policy Research Institute: Washington, DC, USA, 2009; p. 3.

6. Ha, D.T.; Thao, T.D.; Khiem, N.T.; Trieu, M.X.; Gerpacio, R.V.; Pingali, P.L. Maize in Vietnam: Production Systems, Constraints, and Research Priorities; CIMMYT International Maize and Wheat Improvement Center: Mexico, Mexico, 2004; pp. 4-6.

7. Nguyen, T.H. An Overview of Agricultural Pollution in Vietnam: The Crops Sector; World Bank: Washington, DC, USA, 2017.

8. Hallauer, A.R.; Carena, M.J.; Miranda Filho, J.d. Quantitative Genetics in Maize Breeding; Springer Science \& Business Media: New York, NY, USA, 2010; Volume 6.

9. Collard, B.C.; Mackill, D.J. Marker-assisted selection: An approach for precision plant breeding in the twenty-first century. Philos. Trans. R. Soc. Lond. Ser. B Biol. Sci. 2008, 363, 557-572. [CrossRef] [PubMed]

10. Gupta, H.S.; Raman, B.; Agrawal, P.K.; Mahajan, V.; Hossain, F.; Thirunavukkarasu, N. Accelerated development of quality protein maize hybrid through marker-assisted introgression of opaque-2 allele. Plant Breed. 2013, 132, 77-82. [CrossRef]

11. Chandran, S.; Pukalenthy, B.; Adhimoolam, K.; Manickam, D.; Sampathrajan, V.; Chocklingam, V.; Eswaran, K.; Arunachalam, K.; Joikumar Meetei, L.; Rajasekaran, R.; et al. Marker-Assisted Selection to Pyramid the Opaque-2 $\left(\mathrm{O}_{2}\right)$ and beta-Carotene (crtRB1) Genes in Maize. Front. Genet. 2019, 10, 859. [CrossRef]

12. Zunjare, R.U.; Hossain, F.; Muthusamy, V.; Baveja, A.; Chauhan, H.S.; Bhat, J.S.; Thirunavukkarasu, N.; Saha, S.; Gupta, H.S. Development of biofortified maize hybrids through marker-assisted stacking of $\beta$-carotene hydroxylase, lycopene- $\varepsilon$-cyclase and opaque2 genes. Front. Plant Sci. 2018, 9, 178. [CrossRef]

13. Sagare, D.B.; Shetti, P.; Surender, M.; Reddy, S. Marker-assisted backcross breeding for enhancing $\beta$-carotene of QPM inbreds. Mol. Breed. 2019, 39, 31. [CrossRef]

14. Goswami, R.; Zunjare, R.U.; Khan, S.; Baveja, A.; Muthusamy, V.; Hossain, F. Marker-assisted introgression of rare allele of $\beta$-carotene hydroxylase (crtRB1) gene into elite quality protein maize inbred for combining high lysine, tryptophan and provitamin A in maize. Plant Breed. 2019, 138, 174-183. [CrossRef]

15. Zhao, X.; Tan, G.; Xing, Y.; Wei, L.; Chao, Q.; Zuo, W.; Lübberstedt, T.; Xu, M. Marker-assisted introgression of qHSR1 to improve maize resistance to head smut. Mol. Breed. 2012, 30, 1077-1088. [CrossRef]

16. Zhang, X.; Yang, Q.; Rucker, E.; Thomason, W.; Balint-Kurti, P. Fine mapping of a quantitative resistance gene for gray leaf spot of maize (Zea mays L.) derived from teosinte (Z. mays ssp. parviglumis). Theor. Appl. Genet. 2017, 130, 1285-1295. [CrossRef] [PubMed]

17. Asea, G.; Vivek, B.S.; Lipps, P.E.; Pratt, R.C. Genetic gain and cost efficiency of marker-assisted selection of maize for improved resistance to multiple foliar pathogens. Mol. Breed. 2012, 29, 515-527. [CrossRef]

18. Hao, X.; Li, X.; Yang, X.; Li, J. Transferring a major QTL for oil content using marker-assisted backcrossing into an elite hybrid to increase the oil content in maize. Mol. Breed. 2014, 34, 739-748. [CrossRef]

19. Ribaut, J.-M.; Jiang, C.; Gonzalez-de-Leon, D.; Edmeades, G.; Hoisington, D. Identification of quantitative trait loci under drought conditions in tropical maize. 2. Yield components and marker-assisted selection strategies. Theor. Appl. Genet. 1997, 94, 887-896. [CrossRef]

20. Beyene, Y.; Semagn, K.; Crossa, J.; Mugo, S.; Atlin, G.N.; Tarekegne, A.; Meisel, B.; Sehabiague, P.; Vivek, B.S.; Oikeh, S. Improving maize grain yield under drought stress and non-stress environments in sub-Saharan Africa using marker-assisted recurrent selection. Crop Sci. 2016, 56, 344-353. [CrossRef]

21. Bankole, F.; Menkir, A.; Olaoye, G.; Crossa, J.; Hearne, S.; Unachukwu, N.; Gedil, M. Genetic gains in yield and yield related traits under drought stress and favorable environments in a maize population improved using marker assisted recurrent selection. Front. Plant Sci. 2017, 8, 808. [CrossRef]

22. Calderon, C.I.; Yandell, B.S.; Doebley, J.F. Fine Mapping of a QTL Associated with Kernel Row Number on Chromosome 1 of Maize. PLoS ONE 2016, 11, e0150276. [CrossRef] 
23. Bommert, P.; Nagasawa, N.S.; Jackson, D. Quantitative variation in maize kernel row number is controlled by the FASCIATED EAR2 locus. Nat. Genet. 2013, 45, 334-337. [CrossRef]

24. Je, B.I.; Gruel, J.; Lee, Y.K.; Bommert, P.; Arevalo, E.D.; Eveland, A.L.; Wu, Q.; Goldshmidt, A.; Meeley, R.; Bartlett, M. Signaling from maize organ primordia via FASCIATED EAR3 regulates stem cell proliferation and yield traits. Nat. Genet. 2016, 48, 785-791. [CrossRef]

25. Wang, J.; Lin, Z.; Zhang, X.; Liu, H.; Zhou, L.; Zhong, S.; Li, Y.; Zhu, C.; Lin, Z. krn1, a major quantitative trait locus for kernel row number in maize. New Phytol. 2019, 223, 1634-1646. [CrossRef]

26. Peng, B.; Li, Y.; Wang, Y.; Liu, C.; Liu, Z.; Tan, W.; Zhang, Y.; Wang, D.; Shi, Y.; Sun, B. QTL analysis for yield components and kernel-related traits in maize across multi-environments. Theor. Appl. Genet. 2011, 122, 1305-1320. [CrossRef] [PubMed]

27. Cai, L.; Li, K.; Yang, X.; Li, J. Identification of large-effect QTL for kernel row number has potential for maize yield improvement. Mol. Breed. 2014, 34, 1087-1096. [CrossRef]

28. Liu, L.; Du, Y.; Huo, D.; Wang, M.; Shen, X.; Yue, B.; Qiu, F.; Zheng, Y.; Yan, J.; Zhang, Z. Genetic architecture of maize kernel row number and whole genome prediction. Theor. Appl. Genet. 2015, 128, 2243-2254. [CrossRef] [PubMed]

29. Liu, C.; Zhou, Q.; Dong, L.; Wang, H.; Liu, F.; Weng, J.; Li, X.; Xie, C. Genetic architecture of the maize kernel row number revealed by combining QTL mapping using a high-density genetic map and bulked segregant RNA sequencing. BMC Genom. 2016, 17, 1-10. [CrossRef] [PubMed]

30. Zhan, J.; Wang, F.; Xing, W.; Liu, J.; Fan, Z.; Tao, Y. Fine mapping and candidate gene prediction of a major QTL for kernel number per ear in maize. Mol. Breed. 2018, 38, 27. [CrossRef]

31. Taguchi-Shiobara, F.; Yuan, Z.; Hake, S.; Jackson, D. The fasciated ear2 gene encodes a leucine-rich repeat receptor-like protein that regulates shoot meristem proliferation in maize. Genes. Dev. 2001, 15, 2755-2766. [CrossRef]

32. Tran, Q.H.; Bui, N.H.; Kappel, C.; Dau, N.T.N.; Nguyen, L.T.; Tran, T.T.; Khanh, T.D.; Trung, K.H.; Lenhard, M.; $\mathrm{Vi}$, S.L. Mapping-by-Sequencing via MutMap Identifies a Mutation in ZmCLE7 Underlying Fasciation in a Newly Developed EMS Mutant Population in an Elite Tropical Maize Inbred. Genes 2020, 11, 281. [CrossRef]

33. Gerpacio, R.V. Impact of Public-and Private-Sector Maize Breeding Research in Asia, 1966-1997/98; CIMMYT: Mexico, Mexico, 2001.

34. Severini, A.D.; Borrás, L.; Westgate, M.E.; Cirilo, A.G. Kernel number and kernel weight determination in dent and popcorn maize. Field Crops Res. 2011, 120, 360-369. [CrossRef]

35. Seebauer, J.R.; Singletary, G.W.; Krumpelman, P.M.; Ruffo, M.L.; Below, F.E. Relationship of source and sink in determining kernel composition of maize. J. Exp. Bot. 2010, 61, 511-519. [CrossRef]

36. Borrás, L.; Otegui, M.E. Maize kernel weight response to postflowering source-sink ratio. Crop Sci. 2001, 41, 1816-1822. [CrossRef]

37. McMullen, M.D.; Kresovich, S.; Villeda, H.S.; Bradbury, P.; Li, H.; Sun, Q.; Flint-Garcia, S.; Thornsberry, J.; Acharya, C.; Bottoms, C. Genetic properties of the maize nested association mapping population. Science 2009, 325, 737-740. [CrossRef] [PubMed]

38. Larièpe, A.; Mangin, B.; Jasson, S.; Combes, V.; Dumas, F.; Jamin, P.; Lariagon, C.; Jolivot, D.; Madur, D.; Fievet, J. The genetic basis of heterosis: Multiparental quantitative trait loci mapping reveals contrasted levels of apparent overdominance among traits of agronomical interest in maize (Zea mays L.). Genetics 2012, 190, 795-811. [CrossRef] [PubMed]

39. Thiemann, A.; Fu, J.; Seifert, F.; Grant-Downton, R.T.; Schrag, T.A.; Pospisil, H.; Frisch, M.; Melchinger, A.E.; Scholten, S. Genome-wide meta-analysis of maize heterosis reveals the potential role of additive gene expression at pericentromeric loci. BMC Plant Biol. 2014, 14, 1-14. [CrossRef] [PubMed]

40. Fletcher, J.C. The CLV-WUS stem cell signaling pathway: A roadmap to crop yield optimization. Plants 2018, 7,87. [CrossRef]

41. Xu, C.; Liberatore, K.L.; MacAlister, C.A.; Huang, Z.; Chu, Y.-H.; Jiang, K.; Brooks, C.; Ogawa-Ohnishi, M.; Xiong, G.; Pauly, M. A cascade of arabinosyltransferases controls shoot meristem size in tomato. Nat. Genet. 2015, 47, 784-792. [CrossRef]

42. Muños, S.; Ranc, N.; Botton, E.; Bérard, A.; Rolland, S.; Duffé, P.; Carretero, Y.; Le Paslier, M.-C.; Delalande, C.; Bouzayen, M. Increase in tomato locule number is controlled by two single-nucleotide polymorphisms located near WUSCHEL. Plant Physiol. 2011, 156, 2244-2254. [CrossRef] 
43. Yuste-Lisbona, F.J.; Fernández-Lozano, A.; Pineda, B.; Bretones, S.; Ortíz-Atienza, A.; García-Sogo, B.; Müller, N.A.; Angosto, T.; Capel, J.; Moreno, V. ENO regulates tomato fruit size through the floral meristem development network. Proc. Natl. Acad. Sci. USA 2020, 117, 8187-8195. [CrossRef]

44. Rodríguez, G.R.; Muños, S.; Anderson, C.; Sim, S.-C.; Michel, A.; Causse, M.; Gardener, B.B.M.; Francis, D.; van der Knaap, E. Distribution of SUN, OVATE, LC, and FAS in the tomato germplasm and the relationship to fruit shape diversity. Plant Physiol. 2011, 156, 275-285. [CrossRef]

45. Chu, Y.H.; Jang, J.C.; Huang, Z.; van der Knaap, E. Tomato locule number and fruit size controlled by natural alleles of lc and fas. Plant Direct 2019, 3, e00142. [CrossRef]

46. Rodríguez-Leal, D.; Lemmon, Z.H.; Man, J.; Bartlett, M.E.; Lippman, Z.B. Engineering quantitative trait variation for crop improvement by genome editing. Cell 2017, 171, 470-480. [CrossRef]

47. Fan, C.; Wu, Y.; Yang, Q.; Yang, Y.; Meng, Q.; Zhang, K.; Li, J.; Wang, J.; Zhou, Y. A novel single-nucleotide mutation in a CLAVATA3 gene homolog controls a multilocular silique trait in Brassica rapa L. Mol. Plant 2014, 7, 1788-1792. [CrossRef] [PubMed]

48. Nagasawa, N.; Miyoshi, M.; Kitano, H.; Satoh, H.; Nagato, Y. Mutations associated with floral organ number in rice. Planta 1996, 198, 627-633. [CrossRef] [PubMed]

49. Suzaki, T.; Sato, M.; Ashikari, M.; Miyoshi, M.; Nagato, Y.; Hirano, H.-Y. The gene FLORAL ORGAN NUMBER1 regulates floral meristem size in rice and encodes a leucine-rich repeat receptor kinase orthologous to Arabidopsis CLAVATA1. Development 2004, 131, 5649-5657. [CrossRef] [PubMed]

50. Chu, H.; Qian, Q.; Liang, W.; Yin, C.; Tan, H.; Yao, X.; Yuan, Z.; Yang, J.; Huang, H.; Luo, D. The floral organ number4 gene encoding a putative ortholog of Arabidopsis CLAVATA3 regulates apical meristem size in rice. Plant Physiol. 2006, 142, 1039-1052. [CrossRef] [PubMed]

51. Zhang, T.; You, J.; Zeng, X.; Yu, G.; Zhang, Y.; Li, Y.; Ye, L.; Yao, W.; Tu, Y.; Ling, Y. Gene mapping and candidate gene analysis of multi-grains 1 (Mg1) in rice. Crop Sci. 2020, 60, 238-248. [CrossRef]

52. Ye, S.; Yang, W.; Zhai, R.; Lu, Y.; Wang, J.; Zhang, X. Mapping and application of the twin-grain1 gene in rice. Planta 2017, 245, 707-716. [CrossRef] [PubMed]

53. Bommert, P.; Nardmann, J.; Vollbrecht, E.; Running, M.; Jackson, D.; Hake, S.; Werr, W. thick tassel dwarf1 encodes a putative maize ortholog of the Arabidopsis CLAVATA1 leucine-rich repeat receptor-like kinase. Development 2005, 132, 1235-1245. [CrossRef]

54. Je, B.I.; Xu, F.; Wu, Q.; Liu, L.; Meeley, R.; Gallagher, J.P.; Corcilius, L.; Payne, R.J.; Bartlett, M.E.; Jackson, D. The CLAVATA receptor FASCIATED EAR2 responds to distinct CLE peptides by signaling through two downstream effectors. eLife 2018, 7, e35673. [CrossRef]

55. Pautler, M.; Eveland, A.L.; LaRue, T.; Yang, F.; Weeks, R.; Je, B.I.; Meeley, R.; Komatsu, M.; Vollbrecht, E.; Sakai, H. FASCIATED EAR4 encodes a bZIP transcription factor that regulates shoot meristem size in maize. Plant Cell 2015, 27, 104-120. [CrossRef]

56. Bommert, P.; Je, B.I.; Goldshmidt, A.; Jackson, D. The maize G $\alpha$ gene COMPACT PLANT2 functions in CLAVATA signalling to control shoot meristem size. Nature 2013, 502, 555-558. [CrossRef]

57. Rodriguez-Leal, D.; Xu, C.; Kwon, C.T.; Soyars, C.; Demesa-Arevalo, E.; Man, J.; Liu, L.; Lemmon, Z.H.; Jones, D.S.; Van Eck, J.; et al. Evolution of buffering in a genetic circuit controlling plant stem cell proliferation. Nat. Genet. 2019, 51, 786-792. [CrossRef] [PubMed]

58. Agarwal, A.; Yadava, P.; Kumar, K.; Singh, I.; Kaul, T.; Pattanayak, A.; Agrawal, P.K. Insights into maize genome editing via CRISPR/Cas9. Physiol. Mol. Biol. Plants Int. J. Funct. Plant Biol. 2018, 24, 175-183. [CrossRef] [PubMed]

Publisher's Note: MDPI stays neutral with regard to jurisdictional claims in published maps and institutional affiliations.

(C) 2020 by the authors. Licensee MDPI, Basel, Switzerland. This article is an open access article distributed under the terms and conditions of the Creative Commons Attribution (CC BY) license (http://creativecommons.org/licenses/by/4.0/). 